Chemistry is also becoming more serviceable to medicine and all the biological sciences. The psychiatrist is now coming to the chemist for help. Many forms of mental disorder appear to arise from disturbances of metabolism which are revealed by chemical studies, and there is hope that methods of treatment may be found to correct the errors so discovered. If only some forms of insanity can be cured, it would be at least a partial solution of one of the most painful human problems. "Extending this idea, may we not believe that even the psychologist will have to pay attention to chemistry? So intimately interwoven are the activities of mind and body that no one can deny that the psychology of the individual is greatly affected by the hormonic balance which is part of his physical constitution; and hormones owe their specific influence in the body to particular aspects of their molecular structure". Chemistry in fact is ubiquitous, though it required the Great War to make Great Britain realize the truth of Disraeli's dictum that the prosperity of the chemical industry is the best index of the prosperity of the country as a whole.

The distinction between pure and applied science is becoming less real, and it is probable that never before has organic chemistry shown more possibility of continued development. How remarkable in kind the development of organic chemistry has been in its apparently static time. The product of a pictorial, or even artistic rather than mathematical type of intellect, the evolution of the idea of molecular structure was something new and distinct, and the verification by modern physical methods of the conclusions reached is indeed remarkable. Organic chemistry in approaching physics is becoming more dynamic and more subtle.

Biochemistry is a borderland subject (not a hybrid, because it is certainly not infertile), and borderland workers usually find work not found by the cultivators of either of the contiguous regions. Intellectual trust and sympathy between two departments may be very fertile. Biochemistry is the study of chemical dynamics as exhibited in life, and requires a knowledge of the physical properties and molecular structure of the substances which play an essential part in the constitution of living systems. Its special endeavour must be to follow so far as possible the function and fate of each significant constituent amid the multitudinous reactions which underlie the manifestations of life, and to explore the mechanisms which control those reactions. For this work, biochemistry is developing its own technique, and its progress though difficult is real. While immersed in problems so different in kind, it is almost impossible for the specialized biochemist to acquire the knowledge and experience, or the mode of thought and intuitions of the accomplished organic chemist, in determining molecular structure and in the difficult art of synthesis. Even the best biochemist must remain an amateur in organic chemistry. There never was a case in which progress could be better secured by a wise division of labour. Recently organic chemists have been examining the structure of natural products with marked success.

Sir Frederick concluded with a eulogy of the work of the Birmingham University School of Chemistry, referring in particular to the synthesis of vitamin $\mathrm{C}$, the commercial manufacture of which means that no case of scurvy need in future remain uncured.

\title{
Standardization of Physical Units
}

$I^{N}$ a paper by Lyman J. Briggs, director of the National Bureau of Standards at Washington, which appeared in the January issue of the Journal of the Franklin Institute, some of the present-day problems in connexion with securing international uniformity in standards are discussed.

The British inch, derived directly from the imperial yard, is about four parts in a million shorter than the United States unit. But if we use the conversion factor so that one inch equals $25 \cdot 4$ millimetres exactly, then the new value of the inch would fall midway between the British and the United States inch. The Bureau of Standards has definitely proposed that this be done. The change would not affect industry in the slightest because it falls well within the tolerances in industrial measurements. This conversion factor, one inch equals $25.4 \mathrm{~mm}$., has recently been adopted for industrial purposes by standardizing groups in fifteen countries including both England and the United States.

In the field of electricity, the tools of measurement now depend on national standardizing laboratories. The maintenance of units is made possible on a world-wide basis by the rise of the great national standardizing laboratories, especially in Germany, Great Britain and the United States. The revision of the units is under way at the present time. But as the present units are more than sufficiently accurate for industrial use, the changes made will only affect laboratories making very precise measurements. The change will become effective on January 1, 1940. The present 'international' units of the ampere, ohm and volt will be respectively $0.9999,1 \cdot 0005$ and 1.0004 of the new (absolute) ampere, ohm and volt respectively.

The present standards for use in photometry are either flame standards or carbon filament lamps giving light of a yellowish colour, and there is no general agreement as to a method regarding a method of passing over to lamps giving 'whiter' light. The German-speaking countries also never accepted the old 'international candle' but use their own unit, the Hefner, which is only nine tenths of it. Now that the Bureau of Standards has determined the be. haviour of the normal eye in terms of 'factors of luminosity' which have been internationally agreed, a basis has been fixed for measuring lights of any colour provided we have some kind of standard as a starting point. We have still to agree upon the photometric scale for the brightness of the primary standard. The Bureau of Standards has recently suggested that the old 'international candle' be abandoned and that a slightly different unit be fixed by taking the round value of 60 candles per sq. $\mathrm{cm}$., instead of the old value of $58 \cdot 9$, as the brightness of the blackbody radiator at the platinum point. 